\title{
Processos históricos, aprendizagem e educação de uma "segunda natureza humana"
}

\section{Historical processes, learning and education of a "second human nature"}

\author{
Estevão de Rezende Martins ${ }^{1}$
}

\begin{abstract}
RESUMO
Processos históricos é uma expressão corrente na historiografia. A historiografia é um produto que decorre de um processo metódico que identifica questões históricas, planeja sua pesquisa e constrói sua explicação mediante argumento demonstrativo. Na educação histórica, a historiografia-produto participa como componente dos processos de formação cultural das pessoas. Na cultura histórica de todo grupo social tem-se o conteúdo da reflexão historicizante sobre si e sua origem e a prática de transmissão dessa reflexão entre seus integrantes, nas dimensões vertical (passado-futuro) e horizontal (presente). A dimensão horizontal é a plataforma de mediação entre continuidade e mudança na memória coletiva e individual. Para todo e qualquer agente, a cultura histórica é, necessariamente, uma situação dada sob cujo influxo ele atua (aquisição gradual da consciência histórica por mimetismo inicial e por distanciamento crítico). Admitida uma "primeira natureza humana" caracterizada pela racionalidade discursiva e argumentativa, a educação histórica, que use a historiografia, pode ser vista como construtora de uma "segunda natureza", instaurada e desenvolvida na dimensão temporal da existência dos agentes racionais humanos - nos processos educacionais existentes no respectivo meio sociocultural, que instituem hábitos e convicções. $\mathrm{Na}$ tradição histórica ocidental, desde Cícero, ressalta-se o mimetismo inercial da cultura em que se é educado como uma "segunda natureza". Por certo não se considera mais tal "natureza" como uma determinação ontológica, mas como um dado histórico adquirido e modificável. A historiografia moderna demonstra como a análise metódica dos processos históricos desde o
\end{abstract}

DOI: $10.1590 / 0104-4060.46006$

1 Universidade de Brasília. Brasília, Distrito Federal, Brasil. Campus Universitário Darcy Ribeiro. Caixa Postal 04363. CEP: 70904-970.E-mail: ecrm@terra.com.br 
Iluminismo permite entender e explicar a realidade da educação e da consciência históricas adquiríveis nos meios socioculturais dos agentes.

Palavras-chave: cultura histórica; aprendizagem histórica; historiografia; segunda natureza.

\begin{abstract}
Historical processes is a current expression in historiography. Historiography is a product that stems from a methodical process that identifies historical questions, plans its research and builds its explanation upon argumentative statements. In education, historiography as a product participates as a component in the processes of one's cultural education. The historical culture of every social group promotes a historicizing reflection about itself and its origin and about the practice of its transmission among its members in both the vertical (past-future) and horizontal (present) dimensions as well. The horizontal dimension is the platform of mediation between continuity and change in the individual and collective memory. For all and any agent, historical culture is necessarily a given situation, under whose influence he acts (along a gradual acquisition of historical awareness by initial mimicry and then by critical distance). Admitted a "first human nature" characterized by discursive and propositional rationality, the educational process that uses historiography as a source can be seen as a builder of a "second nature", introduced and developed in the temporal dimension of the existence of rational human agents - along the educational process in their present socio-cultural environment, in which habits and convictions are established. In the Western historical tradition, from Cicero onwards, the inertial mimicry of the culture in which one is brought up is emphasized as a 'second nature'. Certainly such a "nature" is not considered anymore as an ontological determination, but as a historic one, acquired and modifiable. Modern history shows how the methodical analysis of historical processes since the Enlightenment allows us to understand and explain the reality of acquirable historical education and awareness in the social and cultural milieus of the agents.
\end{abstract}

Keywords: historical culture; historical learning; historiography; second nature.

"Processos históricos" é uma expressão recorrente na historiografia. Com ela se enuncia um modo de apreender, descrever, entender, explicar e narrar acontecimentos cujo encadeamento permite compreender a situação no tempo atual do sujeito agente e sua possível projeção no futuro. 
O uso de tal expressão, com esse sentido, pressupõe que a historiografia se conceba e pratique como uma maneira de produzir e um produto narrativo que decorrem de um processo metódico que formula questões históricas, planeja sua pesquisa e constrói sua explicação mediante argumento demonstrativo. No meio social, a presença da historiografia ganha relevo na medida em que seu teor serve de fonte "material" para a formatação da educação histórica tanto em geral, de modo difuso na sociedade e na cultura, quanto em particular, no espaço regrado dos diversos níveis escolares. Na educação histórica em geral, a historiografia-produto participa como componente dos processos de formação cultural das pessoas. De certa maneira, a memória coletiva opera com informações transmitidas que se originam, dentre outras fontes, na historiografia (consagrada e utilizada). Na de todo grupo social tem-se tanto o conteúdo da reflexão historicizante de cada um, sobre si e sua origem, quanto a prática de transmissão dessa reflexão entre seus integrantes, nas dimensões vertical (passado-futuro) e horizontal (presente). A dimensão horizontal é a plataforma de mediação entre continuidade e mudança na memória coletiva e individual. Para todo e qualquer agente, a cultura histórica de facto é, necessariamente, um dado a priori em que o agente dá conta de si como um ser atual e sob cujo influxo ele se posiciona (aquisição gradual da consciência histórica por mimetismo inicial e por distanciamento crítico).

a) "Primeira" e "segunda natureza"

É razoável supor que todo agente humano está dotado de uma "primeira natureza", caracterizada pela racionalidade discursiva e argumentativa. Pode-se então considerar a educação histórica, que se valha da historiografia e se dê no âmbito da cultura histórica acumulada, como a construtora de uma "segunda natureza", instaurada e desenvolvida na dimensão temporal da existência dos agentes racionais humanos - nos processos educacionais existentes no respectivo meio sociocultural, que instituem hábitos e conviç̧ões.

$\mathrm{Na}$ tradição histórica ocidental, desde Cícero, vê-se o mimetismo inercial da cultura, na qual se é educado, como uma "segunda natureza". Por certo não se considera mais tal "natureza" como uma determinação ontológica, mas como um dado histórico adquirido e, por conseguinte, modificável. A historiografia moderna tem demonstrado como a análise metódica dos processos históricos também permite entender e explicar a realidade da educação e da consciência históricas adquiríveis nos respectivos meios socioculturais dos agentes. 
Que a cultura tenha o poder de, mediante processos educacionais, criar algo semelhante à natureza e de influenciar nosso comportamento, ao modelá-lo por tais processos, de tal modo que os comportamentos induzidos pareçam naturais e espontâneos, é uma convicção antiga acerca do alcance da cultura, reiterada incontáveis vezes desde Demócrito. Ao elaborar sua teoria da virtude, Aristóteles recorreu a essa convicção e Cícero cunhou a fórmula depois amplamente difundida em todas as línguas europeias, de que o costume torna-se logo uma "segunda natureza" ou produz uma "segunda natureza". (RATH, 1996, p. 112s, 141). Hábitos e costumes profundamente arraigados, normas seguidas desde tempos imemoriais, recomendações e interditos podem adquirir facilmente, para aqueles que vivem no respectivo sistema de valores e referências, um caráter de "coisa natural", sem mesmo que as pessoas cogitem agir de outra forma.

Tais formatações da "natureza culta" dos assim chamados "educandos" são chamadas, frequentemente, na tradição europeia da história cultural, de processos necessários e incontornáveis de transformação de uma "primeira" em uma "segunda" natureza. Uma cultura que tencione preservar-se, por via de consequência, tem de transmitir às gerações subsequentes, da forma mais completa possível, seus modelos tradicionais fundantes, seus sistemas normativos e seus modos de interpretar o mundo e a vida - componentes essenciais de tal "segunda natureza". A maneira mais eficaz de essa preservação-transmissão ocorrer está em os processos educacionais, os conteúdos cognitivos e os hábitos comportamentais parecerem, àqueles que os devem incorporar, pura e simplesmente naturais.

A fórmula do hábito como uma "segunda natureza" (FUNKE, 1958) ou da educação como produtora de uma "segunda natureza" (FUNKE; RATH, 1984) tornou-se uma presença constante nas teorias da "cultura civilizada", concebida como uma dupla forma de reforçar, completar ou corrigir a "primeira natureza". Corrigir: no sentido de que os "instintos" passariam a estar controlados e direcionados por critérios racionais ponderados. Completar: no sentido de que a interação social entre indivíduos estaria sob o comando de tradições e regras que estipulam um critério de pertencimento sociocultural e que viabilizam preservação, continuidade e disciplinamento. Reforçar: no sentido de sustentar a espontaneidade crítica autorreferenciada do sujeito pensante e agente. Tendencialmente, pois, o processo educacional de "revestir" a natureza primeira como uma natureza segunda é conservador. Tal efeito conservador, contudo, não cristaliza irremediavelmente a natureza segunda em uma estrutura intocável. Nem lhe imprime uma marca egocêntrica prevalente. A possibilidade de mudar, alterar, modificar, substituir, suprimir hábitos, costumes, padrões, valores, normas, regras, princípios, é um fato. A razoabilidade de pensar em si sem excluir os demais é afirmada e defendida amplamente nos meios da ética 
e da crítica cultural. A evolução das sociedades e as transformações por que passam demonstram sobejamente essas opções e suas efetivações.

A natureza segunda não é forçosamente resultado de imposição tirânica ou descabida, embora venha a assim parecer, na medida em que cada geração emergente possa sentir-se submetida a uma formatação incontornável. É preciso, contudo, reconhecer que, de fato, a cada geração e a cada indivíduo, o momento originário da relação socioeducacional consiste em uma manifesta imposição da cultura (pre)existente e das opções praticadas, no ambiente sociocultural, pelos antecessores. Cícero lembra, recorrendo a um raciocínio aristotélico, “[...] que no início busca-se apenas o prazer, mas com o tempo surge certo costume que institui como uma segunda natureza, que leva o homem a fazer muitas coisas que já não mais têm a ver com o prazer"2. Tal segunda natureza é, pois, resultado da ação humana para além do modo de viver instintivo - Cícero lança mão do estoicismo: “[...] nós semeamos cereais e plantamos árvores; desviamos água para irrigar nossas terras, tornando-as frutíferas, represamos rios, modificamos seu curso e os reaproveitamos; com efeitos, buscamos criar por nós mesmos, em meio à natureza, uma segunda natureza" ${ }^{\text {"3 }}$. Cícero remete a um contexto típico de nossa própria condição: por falta de meios naturais para tudo e qualquer coisa, dependemos de substitutos produzidos. Por exemplo: quando já não se tem mais peles e couros, ou estes não bastam para todos, é preciso produzir vestimentas e dispor de um sistema social de produção e distribuição de tais bens. Ademais, a sociedade depende de um funcionamento relativamente tranquilo dos mecanismos que garantam a preservação da vida (preferentemente uma cultura que assegure uma vida tranquila e sempre mais confortável), para cuja consecução se tenha o mínimo de desgaste para o máximo de vantagem.

b) "Segunda natureza": interna e externa

Tal expectativa pessoal, espontaneamente constatável, evidencia dois planos da "segunda natureza". Um, interno, deixa entrever que cada indivíduo concebe um horizonte de expectativa, no plano interior, que não meramente

2 "Quin etiam ipsi voluptarii deverticula quaernt et virtutes habent in ore totus dies voluptatemque dumtaxat primo expeti dicunt deinde consuetudine quasi alteram quandam naturam effici, qua impulsi multa faciant nulla quaerentes voluptatem." (CÍCERO, 1914, p. 476).

3 "Terrenorum item commodorum omnis est in homine dominatus: nos campis nos montibus fruimur, nostri sunt amnes nostri lacus, nos fruges serimus nos arbores, nos aquarum inductionibus terris fecunditatem damus, nos flumina arcemus derigimus avertimus, nostris denique manibus in rerum natura quasi alteram naturam efficere conamur." (CÍCERO, 1933/1967, p. 270). 
reproduz padrões "naturais" de sobrevivência (síndrome da sobrevivência ou da continuidade). Outro, externo, mostra como cada indivíduo ajuíza o ambiente social e cultural em que vive (nasce, cresce, atua - e no qual está "formatado") e projeta realização pessoal e ação intencional para além de tal ambiente (e, eventualmente, a ele contraposto). De certa maneira essa dupla "superação" mostra o quanto os indivíduos se dispõem a ir além de sua circunstância (e mesmo de ir contra ela). O jogo interativo entre a "natureza primeira" e a "natureza segunda" não significa que haja uma contraposição negativa entre cultura (como segunda natureza) e natureza (primária). Pelo contrário, a aporia clássica entre saber em que consistem a disposição natural "originária" (duradoura, permanente) (KOCH, 2003) e um eventual caráter "antinatural" da sobreposição cultural (efêmera, contingente) é um pseudoproblema. Tanto Hobbes como Rousseau admitem que o "estado de natureza" a que se referem não passa de um pressuposto metafísico, mesmo se os enunciados que a ele remetem pareçam pertencer a uma ontologia. (STRAUSS, 1953/2009). Assim, a consciência histórica de todo agente humano inclui ambos elementos: a subjetividade intrínseca, originária, do sujeito racional, assim como a cultura histórica que preenche essa consciência de vivências, experiências, memórias de si e de sua sociedade.

Uma mediação ativa, pelo próprio sujeito, é necessária à articulação entre primeira natureza (interna) e segunda natureza (externa). A distinção entre primeira e segunda, entre interna e externa, tem função meramente analítica, pois na consciência histórica os dois planos se articulam, mesclam, mediam, influenciam. Indivíduos de cada tempo histórico são unidades operativas que reúnem suas próprias aptidões "naturais" (corpo e espírito) ao legado histórico de sua "cultura", presente na respectiva memória social. Práticas subjetivas e mundo concreto têm de articular-se, como condição de possibilidade da individuação e da aculturação.

$\mathrm{Na}$ Antiguidade clássica ${ }^{4}$ o campo de operação de tal articulação é o mundo filosófico da virtude, mediante a qual o hábito individual (a prática subjetiva de agir dessa ou daquela maneira em interesse próprio) consegue haver-se com um mundo concreto culturalmente modificado pelo agir, tanto de si quanto de outros, sem que necessariamente o interesse próprio tenha de prevalecer sem restrições por sobre os demais interesses presentes na rede de sociabilidade. A concepção de uma atitude virtuosa conflita, contudo, com as situações em que prevalecem de fato o egoísmo, o egocentrismo ou o nacionalismo ou, ainda, resultados opostos aos projetados.

4 A atitude do autocontrole, da temperança, da medida criteriosa e da autodeterminação,

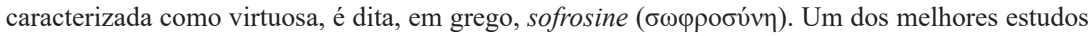
sobre o tema é o clássico de North (1966). 
A ideia de uma virtude de moderação subjetiva e de altruísmo institucionalizado situa-se no plano ideal dos valores transcendentais de tipo ético, em que levar em conta os demais, como se leva em conta a si mesmo, é uma exigência ínsita à natureza humana. Essa lógica virtuosa da ética humana está presente no amor à pólis helênica ou à república romana, tanto como na tradição cristã, na sacralização da figura majestática do soberano, no antropocentrismo moral do Iluminismo. (KOCH, 2013).

c) O Estado moderno como "moldura" da cultura histórica

Pode-se analisar a questão da "segunda natureza" de forma abstrata, mas na realidade o espaço cultural das sociedades está preenchido pelas condições concretas da época em que se encontram os sujeitos. É possível recorrer a uma retrospectiva histórica para entender como e por que a sociedade e a cultura de tal tempo e de tal local são como são. Nas condições presentes, entretanto, parece ser suficiente lembrar que as culturas historicamente constituídas estão - de forma mais ou menos patente - enquadradas pelo Estado em sua versão onipresente contemporânea. A virtude comportamental que se espera de cada agente tem de operar, por conseguinte, em meio às circunstâncias delimitadoras do espaço social, político, econômico e cultural a que pertença.

Com a consolidação do Estado moderno, as questões da gestão da "segunda natureza" de alguma maneira se agudizam. Já não se trata apenas de saber como a "primeira natureza" de um indivíduo lida com a "camada" temporal da cultura que se constitui em sua "segunda natureza" de forma inercial (a memória cultural acumulada se superpõe "espontaneamente" a cada sujeito). A memória, a cultura, o patrimônio intelectual e institucional de uma dada sociedade (em que cada indivíduo se tem de situar) passam a ser "questão de Estado" em processos de centralização política e de gestão ideológica de formas e conteúdos. Os indivíduos já não são apenas "unidades ônticas" autônomas, mas unidades sociais sob o influxo da cultura e de seus gestores.

A expansão do Estado para quase todas as esferas do agir e do pensar, notadamente nos processos educacionais que formatam critérios de agir e ações, coloca - já no século das Luzes - questões sérias quanto às relações entre natureza e cultura. Para iluministas como Kant, Schiller ou Condorcet, o agir humano produz uma esfera cultural como algo novo, cuja natureza é potencialmente superior e, com isso, apta a induzir o progresso histórico. Dois modos de formação da natureza humana convergem: a natureza primeira é pressuposta 
como a aptidão originária de todo e qualquer ser humano de formar-se, a começar pelo agir primário: o trabalho. (HEGEL, 2008, p. 153). Buscar objetivos e alcançá-los mediante agir próprio traz ao ser humano a desejada articulação entre formação interna (constituição da subjetividade histórica consciente) e formação externa (inserção autônoma na cultura histórica "habitada" por outras tantas subjetividades equivalentes).

A formação é uma ferramenta cultural mediante a qual cada sujeito se constitui como indivíduo historicamente consciente e se identifica em meio à diversidade cultural em que se situa e com respeito à qual se distingue. Todo sujeito se forma internamente tanto por recorrer a suas aptidões "naturais" quanto por lidar, conscientemente, com as realidades culturais em cujo conjunto está inserido, como em uma "segunda natureza". A naturalização da cultura histórica como parte integrante da identidade subjetiva de cada indivíduo representa o ápice da relação interioridade-exterioridade, na qual o sujeito se apropria da cultura histórica como uma realidade que não lhe é extrínseca.

Hegel, cuja obra assume a concepção da formação como síntese entre primeira e segunda natureza, ressalta o caráter decisivo do processo da internalização "personalizada" da cultura para entender um "ser educado". (MENKE, 2013, p. 60-81). Por certo há uma dialética poderosa entre a afirmação particular do indivíduo como identidade autônoma e a realidade pesada e imponente da cultura acumulada, cujos valores, práticas, instituições e saberes atuam como um vórtice exteriorizante. A exteriorização é um fato, mas um fato transitório na reflexão autônoma do sujeito. Problemas surgem se o sujeito ficar prisioneiro de tal exteriorização - nesse caso estaríamos diante do conhecido fenômeno da alienação, da exteriorização doentia. O processo educacional tem justamente por objetivo reconhecer o ponto de partida fundante da primeira natureza, seu contato e processo de exteriorização com a segunda natureza e a síntese que se cria, na identidade do indivíduo, mediante o exercício da faculdade crítica de julgar ${ }^{5}$.

Por que seria assim? Pelo fato de a "segunda natureza", presente no acervo cultural multissecular, poder ser também um fator de risco. Com assim? A densidade e o peso acumulado da cultura histórica, que formata a realidade social de cada um, podem tornar-se uma armadura que inviabilize a prática autônoma da reflexão crítica. Esta reflexão é um capital decisivo da "primeira natureza", sem cujo exercício o risco de as pessoas serem engolfadas pela inércia do tempo é muito elevado. Por esse motivo os principais pensadores da virada do século 18 para o século 19 consideraram fundamental entender o processo educacional

5 Ver Helinger, King e Wittwer (2009), esp. os capítulos de Josef Simon (Gegenstand und Selbstbezug [Objeto e autorreferência], p. 63-76) e de J. Nida-Rümelin (Kollektive Selbstbestimmung [Autodeterminação coletiva], p. 193-204). 
da formação como um elemento estratégico para fazer emergir e consolidar-se a autonomia subjetiva dos indivíduos, e não para amalgamá-los numa massa meramente reprodutora da herança inercial.

Tanto o imperativo categórico de Kant quanto a concepção de formação de Humboldt ou ainda a crítica da alienação de Marx têm em comum uma consciência afiada das circunstâncias que a sociedade e seu Estado criaram, mantêm e enrijecem, na expectativa de moldar os indivíduos. É certo que há projetos históricos de organização da sociedade, da economia e do Estado que podem surgir como alternativas tão impositivas quanto as situações que tenderiam a substituir. É o caso de Marx e de seus seguidores.

Como os indivíduos, culturalmente, são formados gradual e longamente, os projetos educacionais não podem negligenciar o problema decorrente da imposição de conteúdos e de formas de pensar e de agir. A institucionalização jurídica e política contemporânea são extremamente extensivas e aparentemente só fazem expandir ainda mais os processos de padronização (centralização, homogeneização) instaurados desde o advento, em meados do século 15 , da forma de Estado moderno. (ROTH, 2003/2011).

Cruzadas as evoluções da precedência cultural histórica (o legado histórico é o capital intelectual inicial de todo sujeito) e da institucionalização dominante do Estado (a estrutura estatal tem prioridade organizacional de fato e de direito), resultou, em particular ao longo do século 19 (mesmo com a variável interveniente da constitucionalização) e ao longo do século 20 (mesmo com as variáveis intervenientes da democratização e dos direitos humanos), a consolidação de processos "formatadores" (mesmo se não necessários em si) que tendem a dar a vantagem à "segunda natureza" por sobre a "primeira". Esforços para inverter tal tendência, costumam ser tipificados como "revolucionários" (em graus diversos de "radicalidade") e os mecanismos de composição (modificações, complementações, supressões do legado cultural e político) usualmente são classificados como "reformistas". (LASKY, 2004). O embate (ou a rivalidade) entre propostas maximalistas (tudo que conste da herança cultural deve ser substituído ou suprimido) e propostas reformistas é tradicional e repetitivo. Mescla uma espécie de conflito entre gerações e uma forma de "reinventar" o mundo a partir de si, a cada vez, em repetidas versões solipsistas de interesse individual ou coletivo (real ou pretendido). De uma ou de outra forma prevalece uma pretensão de alçar-se, mediante a cultura e seu processo de produção e conservação, para acima e para além do "capital inicial" da "primeira natureza". Alçar-se acima e além de si foi por vezes considerado como um abuso de orgulho do ser humano, na mais clássica tradição prometeica. Querer ir além de sua contingência, em uma tentativa de divinização (que Freud chama de "deus protético" (FREUD, 
$1999^{\circ}$ ), é uma aventura e um risco, quando não uma utopia. No entanto, malgrado a aparência de um suplício de Sísifo (CAMUS, 1942, 1991), a constituição de uma "segunda natureza" cultural, sempre em expansão e acumulação, parece ser uma tarefa a que todo e cada indivíduo, em todo e qualquer tempo, se dedica.

\section{d) "Segunda natureza" e cultura histórica}

Do ponto de vista do processo de constituição da consciência histórica e, por conseguinte, do grau (desejado como crescente) de autonomia crítica do sujeito, a "segunda natureza" mediada pela cultura e pela formação não deve (embora possa, para alguns ou para muitos) tornar-se um ergástulo histórico que encarcere o agente. Lidar com a origem, historicamente incontornável, do legado histórico acumulado na cultura não se reduz a reiterá-lo por inércia. Lidar com a cultura histórica significa posicionar-se, assumi-la, transformá-la, ajustá-la, a si e a seu tempo, à sociedade e a seu espaço. Jörn Rüsen, em sua Teoria da História, revista e reorganizada na publicação de 2013 (RÜSEN, 2013, 2015), explica com clareza essa circunstância dialética do existir e do agir humanos: "Cultura histórica é o suprassumo dos sentidos constituídos pela consciência histórica humana" (RÜSEN, 2015, p. 217) - os sentidos são constituídos pelos agentes anteriores, pelos atuais (e, espera-se, pelos futuros), e acumulam-se na memória cultural da(s) sociedade(s). Esses sentidos são, pois, a "matéria-prima" de que está feita a "segunda natureza" herdada, assumida e transformada pela consciência crítica do sujeito.

O processo educacional em que ocorre essa apropriação, "secundária", mas decisiva, pode ser formal ou informal. $\mathrm{O}$ informal é genérico, começa com a gestação do agente e termina com sua morte. Os graus de interação variam ao longo da vida, nos círculos de convivência e nos comportamentos ${ }^{7}$. O formal usualmente se realiza no sistema escolar e nos conteúdos nele tratados, transmitidos e cobrados.

6 “O homem, por assim dizer, tornou-se uma espécie de 'Deus de prótese'. Quando faz uso de todos os seus órgãos auxiliares, ele é verdadeiramente magnífico; esses órgãos, porém, não cresceram nele e, às vezes, ainda lhe causam muitas dificuldades. Não obstante, ele tem o direito de se consolar pensando que esse desenvolvimento não chegará ao fim exatamente no ano de 1930 A.D. As épocas futuras trarão com elas novos e provavelmente inimagináveis grandes avanços nesse campo da civilização e aumentarão ainda mais a semelhança do homem com Deus." (FREUD, 1999, p. 18). (FREUD, 1996, 2010).

7 Diversos ramos da Psicologia ocupam-se desse mosaico interativo. Uma dessas vertentes é a psicologia educacional, na qual se destacam Jean Piaget, Carl Rogers ou Reuven Feuerstein. 
Uma das fontes mais relevantes para o "preenchimento" da cultura histórica na modernidade é a historiografia. Um dos campos da historiografia aplicada é o que produz e utiliza livros ou manuais didáticos, no âmbito do processo formal de ensino e aprendizagem no sistema escolar.

É necessário ter presente que "história" é um nome genérico que se aplica ao conjunto (à totalidade suposta) de todo e qualquer agir humano, em qualquer tempo ou lugar. (MARTINS, 2012). O mesmo termo se aplica à especialidade metódica que investiga atores e ações no tempo, a "ciência da história". Fala-se de história também ao se referir a "livro de história". O uso corrente do termo está, pois, marcado por certa imprecisão. A história como ciência “[...] se legitima pela relação com a experiência mediada pelos conceitos, pelo controle crítico da experiência, pela argumentação explicativa e pelo progresso cognitivo mediante pesquisa". (RÜSEN, 2015, p. 219). O produto específico da história como ciência é, pois, a historiografia. No espaço de cultura histórica em que o indivíduo forma e opera sua consciência histórica convivem e interagem, pois, duas dimensões da história: a genérica, presente na memória pessoal e coletiva, e a específica, presente no "livro de história" tecnicamente reconhecido como historiografia.

$\mathrm{O}$ conjunto dos agentes racionais humanos tem de se haver, por conseguinte, desde diferentes patamares existenciais e culturais, com uma "realidade de segunda ordem" preenchida pela ação de outrem (cronológica ou logicamente precedente ou coetânea) e pela ação própria. Um professor em sala de aula está, de modo manifesto, em patamar diverso daquele em culturalmente que se encontram seus alunos. O mesmo vale para as relações familiares e sociais em geral.

No plano histórico, o processo de aprendizagem dá-se, por conseguinte, em vários planos. A constituição da consciência histórica se processa no aprendizado do convívio e da transmissão de conteúdos (no mais das vezes linguísticos, valorativos e comportamentais) em família e comunidade. Por decorrência da institucionalização da sociedade na forma do Estado moderno, o plano do aprendizado planejado e tutelado (como ocorre no sistema escolar regulado de ensino, aprendizagem e avaliação) possui relevância própria. Para a memória social e individual, a aprendizagem controlada pelos mecanismos instrucionais adquire um peso grande no "preenchimento" da consciência histórica do indivíduo, em meio à cultura histórica acumulada (e prevalente no mundo de sua vida). A cultura histórica dispõe assim de uma dupla potencialidade: a de manter o legado e a de admitir sua transformação pela reflexão crítica e pela ação transformadora dos indivíduos. O legado se exprime em sínteses históricas tendentes a reproduzir e preservar a unidade identificadora do indivíduo, do grupo, da comunidade, da sociedade. A autonomia crítica dos indivíduos e as modificações por eles promovidas demonstram que diversificações e alterações são possíveis e efetivas. 
A diversidade desafia, pois, inevitavelmente, as sínteses. As sínteses simplificam, inexoravelmente, a multiplicidade de facetas da realidade. A realidade experimentada é sempre apenas parcialmente apreendida e apropriada. A realidade do passado histórico só sobrevive pelos vestígios, pela memória e pelo relato de outros. Kant tinha toda razão em afirmar que o que existe somente sobrevive na minha experiência da maneira como eu o registro, processo e incorporo. (KANT, 1968, p. 288-290). A coisa em si (passado real) torna-se fenômeno (memória, consciência, cultura). De certa maneira, a coisa em si é uma "primeira matéria" e o fenômeno uma "segunda matéria", em analogia com a "primeira" e a "segunda" natureza.

A cultura como uma "segunda natureza" consolidada ao longo do tempo e da ação humana é vista, pelo pensamento das Luzes, na segunda metade do século 18 e em seu desdobramento na organização das universidades (nos formatos utilizados até hoje), no início do século 19, como relevante e significante para a contemporaneidade. Por que assim? Pelo fato de a cultura acumulada ser, de certa maneira, a expressão mesma da humanidade, da natureza própria ao agente humano - o modo pelo qual tal agente se define, afirma e sustenta. Como mencionado antes, a autoformação do agente é a forma que a "segunda natureza" toma no interior mesmo da pessoa ("segunda natureza interna"). A formação que leva em conta os demais e o ambiente cultural em que convivem é uma "segunda natureza externa". A correlação entre ambas as formas e formações gerou o imenso legado de cultura que, historicamente, constitui o "meio ambiente" atual de todo agente. No século 21, com a expansão crescente dos desdobramentos tecnológicos da correlação natureza-cultura e com o aparente predomínio da intervenção humana nos processos naturais (o que inclui seus efeitos distorcivos e nocivos, como no recente caso do rompimento de barragens de contenção de rejeitos de mineração em Minas Gerais, no Brasil, em 2015), a "segunda natureza" aparenta tomar-se por superior e intocável ${ }^{8}$. Na cultura contemporânea, fortemente marcada pela experiência do Iluminismo e da conquista da autonomia política no espaço social e estatal, os processos históricos de aprendizagem ganharam acentuadamente em independência crítica, em contraste com o carreamento das tradições, tendentes a acentuar a exemplaridade do passado para gerar o bom cidadão do presente. Algumas indicações do contexto em que essa evolução da consciência histórica do aprendizado chegou até nós.

8 A relação do homem com a natureza mediada pela cultura (notadamente científica e tecnológica) suscita com frequência cada vez maior reservas de cunho ético, pelos efeitos prejudiciais à sobrevivência da humanidade e do meio ambiente. O campo social da "educação ambiental" vem ganhando espaço, inclusive nas instituições formais de ensino. Como introdução, ver Reigota (2001); ver também Jacobi (2003). Como no caso dos Direitos Humanos no século 20, a questão ambiental torna-se estratégica (além de aguda) no século 21. Sobre os desafios de um possível choque entre "segundas naturezas", vale remeter a Beck (1986/2010), embora não recorra a esse conceito. 
e) Educar para a "humanidade"

Na virada para o século 19, o mundo dos irmãos Wilhelm (1767-1835) e Alexander (1769-1859) von Humboldt corresponde a transformações excepcionais, nos planos político, econômico, social e cultural. O ambiente intelectual na "nova" Europa em 1815 era favorável a que se repensasse o projeto de formação do indivíduo em um mundo transformado. Assim, refletir sobre quem é - ou deve ser - $\mathrm{o}$ ator da realização do homem, da sociedade, do estado, do mundo, enfim, estava, por assim dizer, na ordem do dia. Assim, uma das questões que se põe aos (re)organizadores do estado no início de século 19 é: que homem, que cidadão deve ser? Essa questão pode ser tratada de múltiplas maneiras. A resposta da ideia central de Humboldt é: educar para a humanidade.

Humanidade, aqui, é tomada em seus dois sentidos: (a) o que representa o coletivo dos seres humanos, sua totalidade humana concreta e empiricamente existente [meramente suposta, por inumerável], (b) e o sentido que exprime a quintessência do ser humano, sua substância, sua diferença específica. Entendida em ambos os aspectos, humanidade é um conceito que passou a ser articulado de forma irreversível, na virada do século 18 para o 19, com os conceitos de cultura e educação. Friedrich Niethammer (1766-1848), na linha de pensamento de Herder (1774-1803), o diz em 1808 de modo significativo: o homem inteiro é uma razão unificada em um todo estupendo das mais diversas faculdades e disposições. A formação perfeita, multiabrangente e harmônica para constituir o todo, é o ideal da humanidade. A unidade pessoal do indivíduo é definida como fruto da autoformação e da ação educativa ${ }^{10}$. A educação/formação é assim considerada como um processo contínuo de desenvolvimento das próprias possibilidades do homem que se enraíza na capacidade humana de aperfeiçoar-se e se desdobra gradativamente ao longo do tempo. Vista assim, a educação se enuncia como o fim mesmo da existência humana; o homem que se educa é fim de e em si mesmo - a autoeducação é a meta máxima a que pode aspirar.

Para Wilhelm von Humboldt, formar-se (no sentido de educar-se) em si mesmo e a si mesmo é a finalidade do homem enquanto tal. E mais: Friedrich Schlegel (1772-1829) afirma que somente a formação faz do homem a totalidade

9 Tema anteriormente tratado, em versão mais extensa, em Estevão de Rezende Martins. Educar para a humanidade. História e Iluminismo. (ROHDEN, 2002, p. 63-92).

10 Der Streit des Philanthropinismus und Humanismus in der Theorie des ErziehungsUnterrichts unsrer Zeit. Jena: Frommann, 1808. [A polêmica da filantropia e do humanismo na teoria da educação e do ensino em nosso tempo]. Disponível em: $<$ http://www.deutschestextarchiv. de/book/show/niethammer_philantropinismus_1808>. Acesso em: 03 jan. 2016. 
que é sua vocação própria, integralmente humana, perpassada de "humanidade". A ideia da autorrealização do homem pela formação abrange os aspectos que conformam sua existência, incluído o caráter de autonomia, de autossuficiência, na efetivação de suas capacidades.

Friedrich Koch (1769-1849) definiu, em 1811, o princípio ampliado da formação para a humanidade como o desenvolvimento de todas as faculdades especificamente humanas mediante as quais o homem deve tornar-se o que deve $\operatorname{ser}^{11}$. Essa concepção do processo de formação do homem em homem articula com clareza três dimensões da questão. A primeira é a formação, distinta do processo escolar de ensino. A segunda é a humanidade enquanto coletivo de sujeitos individuais concretos, historicamente determinados, que têm de encontrar, nos caminhos do processo formativo, o rumo da sua natureza. A terceira é a humanidade neste último sentido: o caráter humano do modo de ser, em si (real ou suposto) dos homens, singular e coletivamente. Koch fala ainda da discrepância existente entre o ideal clássico de formação elaborado pelo Iluminismo das três últimas décadas do século 18 e o processo educativo social para produzir membros de grupos ou classes sociais ou ainda artesãos e profissionais de tal ou qual ofício. Trata-se de uma discrepância que em nada perdeu sua atualidade. É a que subsiste entre "formação humana" e "formação profissional", entre "perfeição" e "utilidade". Johann-Heinrich Pestalozzi (17461827) defende claramente a hierarquização da formação profissional e de classe sob a finalidade última da formação humana. Da subordinação da formação do cidadão à formação do homem decorre o programa da educação: "O ginásio [ou seja: a escola] deve formar primeiro o homem, depois o cidadão".

\section{f) Sujeito histórico e formação para a autonomia}

Uma concepção desse tipo não pensa em multiplicidade cultural e não lida com diversidade de opiniões. Ambas estariam, no plano da realidade histórica, aquém do projeto da humanidade em si. A serviço deste projeto, contudo, de um - poderíamos dizer assim - "homem ideal", de um "homem segundo um figurino substantivo", estaria a escola "universal" do homem plenamente efetivado, uma "segunda natureza" "pilotada" por um projeto público de sociedade. A dignidade máxima do homem estaria em ser um homem "formado" (pleno), senhor de sua "segunda natureza”, e não em ser um homem "útil”. É por esse

11 Die Schule der Humanität. Leipzig, 1811. [A escola da humanidade]. 
modelo que Wilhelm von Humboldt se pronuncia em 1792: "Não tenho ambição alguma que se pareça com talento, saber, erudição; mas gostaria efetivamente de pretender ser um homem, um homem formado"12. "Formação" não quer dizer aqui um produto do "isolamento" ou da "liberdade" de uma individualidade absolutizada, mas constitui-se, enquanto todo maximamente harmonioso e mais bem proporcionado de todas as faculdades humanas, no projeto da sociabilidade histórica. "Formação", como unidade originária na compreensão de si próprio e do mundo se contrapõe ao sintoma da "unidimensionalidade" do homem na cultura moderna - diagnosticado como ameaçador; contrapõe-se igualmente a qualquer forma de dominação do homem, a qualquer forma de heteronomia. A formação adquire assim uma função política não negligenciável.

Humboldt, para quem "formar o homem" não significava educá-lo para fins heterônomos e que não considera admissível sacrificar o homem ao cidadão, entende que a formação humana deve ser mais livre (ou seja: crítica) e menos vinculada à educação (formal) para a cidadania (vinculada ao Estado). Isso pode parecer paradoxal, hoje em dia e no contexto das sociedades contemporâneas. Com efeito, em sociedades em que a experiência autoritária de governo estigmatizou direitos dos mais elementares, como o de exercer a cidadania política no Estado, "educar para a cidadania" tornou-se uma bandeira de redenção. "Cidadão", para Humboldt e seus contemporâneos, contudo, designa o papel político do homem na sociedade organizada, com efeito sob a forma de Estado - mas não de qualquer estado, mas sim de um Estado que tenha desenho e desígnios certos. Isso não mudou muito de seu tempo para hoje.

$\mathrm{Na}$ transição do Antigo Regime para o período pós-napoleônico, havia fundada desconfiança para com a "educação para a cidadania" - que poderia significar colocar os homens incondicionalmente a serviço do Estado. E todo Estado tem, digamos assim, “donos do poder". Não resta dúvida que, então como hoje, certo grau de desconfiança com os "donos do poder" é sempre bem-vinda. (FAORO, 1958). O Estado mínimo e a liberdade máxima para a formação e para a ação do homem, em seu entendimento são, resumem o essencial da concepção espontaneísta de Humboldt, bem inserida em uma tradição esclarecida e libertária do período que emerge entre aproximadamente 1780 e 1820 e se estende até os albores do século 20. A obra-referência de Humboldt, Ideias para uma tentativa de determinar os limites da ação do Estado, teve influência marcante sobre o famoso tratado de John Stuart Mill (1806-1873), On Liberty (1859).

12 Ideen zu einem Versuch, die Gränzen der Wirksamkeit des Staats zu bestimmen (1792). Breslau: Trewendt, 1851. [Ideias para uma tentativa de determinar os limites da ação do Estado]. Disponível em: <http:/www.deutschestextarchiv.de/book/images/humboldt_grenzen_1851>. Acesso em: 03 jan. 2016. 
Somente o homem de formação plenamente livre, autônoma, independente, pode decidir se "ingressa" ou não no Estado, julgando a constituição deste por comparação a si, no âmbito da "segunda natureza" de uma cultura histórica apropriada criticamente. Há certa dose de abstração nessa visão das coisas, na medida em que, empiricamente, todos nascemos em um mundo carregado de História. E a história concreta das sociedades, pelo menos desde a Idade Moderna, inclui o Estado ou alguma forma dele. Tem-se aqui um ponto nodal da questão: reformar o mundo pela educação, viabilizar a formação de agentes racionais humanos senhores de si são ações que permitem criar a distância crítica para que o "homem bem formado" ajuíze sobre seu mundo, sua sociedade, seu Estado, sua cultura.

O sentido do Iluminismo - em uma acepção dupla: a do esclarecimento enquanto projeção de luz, que faz fugirem as sombras e a do esclarecimento como processo de desvendamento, de explicação - tem, pois, desde a definição magistral de Kant em 1783, o matiz da superação de uma limitação de que é responsável seu próprio autor/ator: o homem. Libertar-se de uma imaturidade, de uma menoridade - mesmo se culposa - é uma missão constante. A observação de Kant não se restringe a um momento temporal determinado, mas refere-se a uma situação intrínseca à condição humana. Essa situação é típica de todo e qualquer homem que deva chegar à idade da razão. Nela, lhe é imperioso aprender a servir-se de seu entendimento sem a tutela de qualquer outro. Anos antes, no prefácio à Crítica da Razão Pura (1781), Kant já destacava que sua época é a da crítica, à qual tudo se deve submeter.

O que Kant sinaliza, no ponto alto do projeto esclarecido de emancipação da razão e do entendimento humanos, era compartilhado por seus contemporâneos. Essa contemporaneidade não se restringe a seus coetâneos, mas estende-se a uma contemporaneidade ideal-típica, a uma comunidade virtual sediada na cultura histórica de uma "segunda natureza", que constitui uma ágora crítica, espaço supranacional e supraideológico da cidadania do mundo inteligível.

\section{g) Aprendizagem e emancipação}

Em que consiste a atitude básica dessa reflexão emancipadora no processo histórico educacional? Podem-se destacar três componentes fundamentais: (a) o engajamento esclarecedor, iluminador, desvelador; (b) a atitude liberal-democrática; (c) a cientificidade rigorosa e produtiva. A dimensão histórica é comum aos três componentes. Na medida em que se sabe que agente racional 
humano algum nasce em um mundo sem História e que toda sociedade é historicamente concreta, à qual correspondem uma consciência histórica e uma cultura determinantes da concepção do tempo, da origem, da evolução e das metas que organizam o agir. Assim, a perspectiva histórica estruturante é fundamental. A investigação histórica (e seu produto: a historiografia) fornece os elementos empíricos que identificam os agentes, seus agrupamentos, suas formações sociais, seus componentes mentais, suas opções intelectuais, suas decisões políticas, suas formas de produção econômica, seus modos de institucionalização estatal. A historiografia, por conseguinte, exerce uma função social crítica que esteia o exame do homem e de sua circunstância. O espírito das Luzes deu forma ao interesse social e científico pela história, em particular no aspecto da crítica da tradição e a sensibilidade individual e coletiva quanto à mudança, à educabilidade, ao aperfeiçoamento.

Independentemente das interpretações restritivas, deterministas ou fatalistas construídas ao longo do século 19 e fortemente politizadas durante o século subsequente, a posição iluminista trouxe para a ciência histórica moderna quatro inovações de monta: (a) a ideia de progresso - isto é, a humanidade, tomada enquanto coletivo-singular (nas duas acepções enunciadas acima) como referência de perfectibilidade constante do agente, de suas razões, de seus motivos, de seus objetivos; (b) os métodos rigorosos de controle da validade das asserções, cujo fundamento é a pesquisa empírica e a intersubjetividade; (c) a perspectividade do conhecimento histórico - vale dizer: qualquer conhecimento histórico é sempre construído (embora não inventado) a partir de certo ponto de vista (habitualmente teórico) e carece de sustentação; do que decorre a quarta inovação: (d) a forma expositiva do conhecimento histórico deve ser sistematicamente argumentativa, demonstrativa. A ciência histórica fornece, por conseguinte, com a densidade do controle metódico da teoria e da prática de pesquisa, a tessitura explicativa das necessidades de autoidentificação dos agentes racionais humanos, mediante referência crítica ao presente, sem, contudo, submeter-se a este ou deixar-se por ele instrumentalizar. Assim, "luzes" têm sempre a ver com conduta metódica, com racionalização, com disciplina, com autocontrole, estabelecendo ordem e contenção na espontaneidade. A crítica, que se exprime por uma dúvida metódica, deve, pois, começar pelo próprio "meio ambiente" cultural em que cada um se encontra. Ao longo do século 20 o itinerário dos Estados e a fragilidade das sociedades condicionaram o surgimento de um ceticismo crescente quanto à possibilidade de qualquer instituição que seja poder conduzir evoluções socioculturais complexas e levar os homens (ou a humanidade, no sentido do coletivo singularizado) a uma práxis histórica efetiva como sujeitos conscientes da ação no tempo. A História, com sua chamada à consciência clara dos percursos reais dos homens e de suas sociedades, 
contribuiria com o "roteiro" de construção da identidade e com o "porto seguro" nos vendavais das transformações valorativas, econômicas e políticas. O agente racional humano, formado nos processos históricos educacionais de seu tempo, de seu meio social e de seu ambiente cultural, aprende a assenhorear-se de sua "segunda natureza" e, por conseguinte, a ser um protagonista efetivo em sua contemporaneidade.

\section{REFERÊNCIAS}

BECK, U. Sociedade de Risco. Rumo a uma outra modernidade. São Paulo: Editora 34, 2010. (original alemão de 1986).

CAMUS, A. The Myth of Sisyphus and Other Essays. Nova Iorque: Vintage Books, 1991. (original francês Le Mythe de Sisyphe. Paris: Gallimard, 1942).

CÍCERO. De finibus bonorum et malorum V, XXV [74]. Trad. e coment. de: RACKHAM, H. Londres: W. Heinemann/Nova Iorque: MacMillan, 1914.

CÍCERO. De natura deorum academica, LX, 162. In: RACKHAM, H. (Ed.). Obras completas de Cicero. Cambridge University Press; Londres: W. Heinemann, 1933. (reimpr. 1967).

FAORO, R. Os donos do poder. Porto Alegre: Globo, 1958.

FREUD, S. O mal-estar na civilização. In: FREUD, S. Obras psicológicas completas de Sigmund Freud: edição standard brasileira. Rio de Janeiro: Imago, 1996.

FREUD, S. Das Unbehagen in der Kultur (1930). In: FREUD, A. et al. (Org.). Gesammelte Werke. Chronologisch geordnet. Frankfurt/Main: Fischer, 1999. v. XIV.

FREUD, S. O mal-estar na cultura. Tradução de: ZWICK, Renato. Revisão técnica de: SELIGMANN-SILVA, M. Porto Alegre: L\&PM, 2010.

FUNKE, G. Gewohnheit [Hábito]. In: ROTHACKER, E. (Org.). Archiv für Begriffsgeschichte-Bausteine zu einem historischen Wörterbuch der Philosophie. Bonn: Bouvier, 1958.

FUNKE, G.; RATH, N. Natur, zweite [Natureza, segunda]. In: Historisches Wörterbuch der Philosophie. Stuttgart: Schwabe, 1984. v. 6, col. 484-494.

HEGEL, G. W. F. Fenomenologia do Espírito (1807). Petrópolis: Vozes, 2008.

HELINGER, J.-Chr.; KING, C. G.; WITTWER, H. (Org.). Identität und Selbstbestimmung [Identidade e autodeterminação]. Berlim: Akademie-Verlag, 2009. 
JACOBI, P. Educação ambiental, cidadania e sustentabilidade. Cadernos de Pesquisa, v. 118, p. 189-205, 2003.

KANT, I. Prolegômenos (1783). Die transzendentalen Hauptfragen, $1^{\text {a }}$. Parte, nota II (Kants Werke. Akademie-Textausgabe, v. IV. Berlim: Walter de Gruyter \& Co., 1968. p. 288-290.

KOCH, L. Kants ethische Didaktik [A didática ética de Kant]. Würzburg: Ergon 2003.

KOCH, L. Lehren und Lernen. Wege zum Wissen [Ensinar e aprender. Caminhos do saber]. Paderborn: Schöningh, 2013.

LASKY, M. J. Utopia and Revolution. On the Origins of a Metaphor. Londres: Transactions Publishers, 2004.

MARTINS, E. de R. O conhecimento histórico e sua rede fatorial. In: PRADO, M. E.; MUNTEAL, O. (Org.). Francisco Falcon. O ofício de historiador. Rio de Janeiro: Revan, 2012. p. 99-121.

MENKE, Chr. Hegels Theorie der Befreiung. Gesetz, Freiheit, Geschichte, Gesellschaft [A teoria de Hegel da Libertação]. In: SCHMIDT, C. (Org.). Können wir der Geschichte entkommen? Geschichtsphilosophie am Beginn des 21. Jahrhunderts. Frankfurt am Main/ Nova Iorque: Campus, 2013. p. 60-81.

NORTH, H. Sophrosyne: Self-Knowledge and Self-Restraint in Greek Literature. Cornell University Press, 1966.

RATH, N. Zweite Natur [Segunda natureza]. Konzepte einer Vermittlung von Natur und Kultur in Anthropologie und Ästhetik um 1800. Münster: Waxmann, 1996.

REIGOTA, M. O que é educação ambiental. São Paulo: Brasiliense, 2001. (Coleção Primeiros Passos).

ROHDEN, V. (Org.). Ideias de Universidade. Canoas: ULBRA, 2002.

ROTH, K. Genealogie des Staates. Prämissen des neuzeitlichen Politikdenkens [Genealogia do Estado]. Berlim: Duncker \& Humblot, 2003. (ed. revista e ampliada: 2011).

RÜSEN, J. Historik. Teorie der Geschichtswissenschaft. Colônia: Böhlau, 2013.

RÜSEN, J. Teoria da História. Uma teoria da história como ciência. Tradução de: MARTINS, Estevão C. de Rezende. Curitiba: Editora da UFPR, 2015.

STRAUSS, L. Direito natural e política. Coimbra: Edições 70, 2009. (original inglês de 1953).

Texto recebido em 22 de março de 2016.

Texto aprovado em 27 de março de 2016. 
